\title{
A FORMAÇÃO EM QUESTÕES DE GÊNERO NO PODER JUDICIÁRIO: UM RELATO DE EXPERIÊNCIA
}

\author{
EDUCATION ON GENDER ISSUES IN THE JUDICIAL \\ POWER: AN EXPERIENCE REPORT
}

\begin{abstract}
ADRIANA RAMOS DE MELLO
Juíza de direito. Doutora em direito público e filosofia jurídico-política pela Universidade Autônoma de Barcelona. Professora da Emerj e do PPGPD/Enfam. https://orcid.org/0000-0002-1756-6786

"O feminismo tem de estar na vanguarda da mudança social efetiva para que sobreviva como movimento em qualquer país." Audre Lord, A. Burst of light.
\end{abstract}

\section{RESUMO}

O artigo proposto tem como objetivo demonstrar a relevância de se capacitar e complementar a formação de magistrados por meio de estudos específicos de questões de gênero. Debate relevante e de conteúdo necessário que, na realidade, deveria ser abordado desde a formação inicial, na graduação em direito, tendo em vista que o Brasil é repleto de desigualdades sociais, políticas, econômicas, de gênero e raça. Utiliza-se como foco da discussão nossa experiência pessoal ao lecionar a disciplina Questões de Gênero para os juízes que iniciam a carreira na Escola Nacional de Formação e Aperfeiçoamento de Magistrados Enfam. Trata-se de tema complexo a ser tratado no âmbito da Justiça, que traz em sua essência estruturas enraizadas do patriarcado, do racismo e do sexismo, mas que precisam ser debatidas e ressignificadas.

Palavras-chave: gênero; feminismo; formação de magistrados; minorias; violência contra a mulher. 


\section{ABSTRACT}

This paper aims at showing the relevance of training as well as complementing the training of judges through specific studies of gender issues. The topic gives rise to relevant debates and includes essential content that, in fact, should have been addressed from the initial studies, in undergraduate courses in Law, specially considering that Brazil is a country full of social, political, economic, gender and race inequalities. The reflections herein focus on my personal experience teaching the subject Gender Issues for judges who are starting their careers at the The Brazilian National Judicial School for Formation and Development - Enfam. This is a complex issue to be dealt with in the field of justice, which has in its core deep rooted structures of patriarchy, racism and sexism, but which must be discussed and given new meaning.

Keywords: gender; feminism; judge training; minorities; violence against women.

Recebido: 21-6-2021

Aprovado: 28-6-2021

\section{SUMÁRIO}

1 Introdução. 2 Os estudos de gênero e a violência contra a mulher. 3 A formação em questões de gênero no Poder Judiciário. 4 Do tema "questões de gênero" na formação judicial. 5 Conclusão. Referências.

\section{INTRODUÇÃO}

O artigo propõe-se a relatar o desafio de lecionar a disciplina Questões de Gênero, na formação inicial e continuada no âmbito do Poder Judiciário, a partir de uma experiência no módulo nacional da Escola Nacional de Formação e Aperfeiçoamento de Magistrados Enfam?'.

\footnotetext{
1 "A Escola Nacional de Formação e Aperfeiçoamento de Magistrados (Enfam) é o órgão oficial de treinamento de juízes de direito e juízes federais brasileiros. A ela cabe regulamentar, autorizar e fiscalizar os cursos oficiais para ingresso, vitaliciamento e promoção na carreira da magistratura. Prevista originalmente na Emenda Constitucional n. 45, que promoveu mudanças na estrutura do Poder Judiciário, a Escola foi instituída em 30 de novembro de 2006, por meio da Resolução n. 3 do Superior Tribunal de Justiça." (ESCOLA NACIONAL DE FORMAÇÃO E APERFEIÇOAMENTO DE MAGISTRADOS, [2021])
} 
Em que pese o Brasil ter ratificado importantes documentos internacionais, como a Convenção para a Eliminação de todas as Formas de Discriminação contra as Mulheres - Cedaw e a Convenção Interamericana para Prevenir, Punir e Erradicar a Violência contra as Mulheres (Convenção de Belém do Pará), que contêm garantias à igualdade de sexo/gênero perante a lei e obrigações de assegurar que todos se beneficiem de igual proteção, a realidade das mulheres brasileiras está muito distante do cumprimento dessas convenções.

De acordo com o Comitê Cedaw da Organização das Nações Unidas, a discriminação contra as mulheres baseada em estereótipos de gênero, estigmas, normas culturais nocivas e patriarcais tem um impacto direto no direito de acesso à justiça com base na igualdade com os homens. Além disso, outros fatores afetam as mulheres em graus ou modos diferentes daqueles que atingem homens ou mulheres, como raça/etnia, condição indígena ou minoria, cor, idade, religião ou crença, origem nacional, deficiência, identidade como mulher lésbica, bissexual ou transgênero ou pessoa intersexual. Mulheres que pertencem a esses grupos têm mais dificuldade para acessar a justiça. (NAÇÕES UNIDAS, 2015)

O movimento de mulheres teve uma participação intensa nos debates que antecederam 1988 visando à incorporação dos direitos das mulheres no âmbito da Constituição Federal, o que resultou na elaboração da Carta das Mulheres Brasileiras aos Constituintes, documento de extrema importância (aliás, pouco conhecido) no qual constam as grandes reivindicações dos direitos das mulheres, fruto de um significativo debate nacional. Todos os direitos conquistados pelas mulheres naquela ocasião se devem à articulação dos movimentos sociais de mulheres de todo o Brasil, o que resultou na inclusão das principais reivindicações na Carta de 1988. (MARIA et al., 1987)

No entanto, o movimento feminista tradicional sempre recebeu severas críticas do movimento feminista negro porque não contemplava as reivindicações das mulheres negras. Sueli Carneiro, em relação ao silêncio e à invisibilidade das mulheres negras, enfatiza:

Enegrecendo o feminismo é a expressão que vimos utilizando para designar a trajetória das mulheres negras no interior do movimento feminista brasileiro. Buscamos assinalar, com ela, a identidade branca e ocidental da formulação clássica feminista, de um lado; e, de outro, revelar a insuficiência teórica e prática política para integrar as diferentes expressões do feminino construídos em sociedades multirraciais e pluriculturais. (CARNEIRO, 2003) 
Apesar de todos os avanços alcançados no âmbito internacional com as leis Maria da Penha e do Feminicídio, a realidade brasileira revela um grave padrão de desrespeito aos mais elementares direitos das mulheres: a violência de gênero contra a mulher, a discriminação contra as mulheres e os obstáculos no acesso à justiça.

O Comitê Cedaw observou ainda que os estereótipos de gênero no sistema judicial têm consequências de amplo alcance para o pleno desfrute pelas mulheres de seus direitos humanos e recomendou que os estados-partes adotem medidas, incluindo programas de conscientização e de capacitação aos agentes do sistema de justiça para eliminar os estereótipos e incorporar a perspectiva de gênero em todos os aspectos do sistema de justiça. (NAÇÕES UNIDAS, 2015)

Os estudos de gênero e violência contra a mulher no âmbito das formações judiciais têm um papel relevante. Caracterizam-se como ferramenta política emancipatória, uma vez que as escolas da magistratura correm o risco de reproduzir todos os equívocos das faculdades de direito com uma "formação jurídica antiquada", sem nenhuma concepção interdisciplinar (SANTOS, 2011). E é nesse contexto que a Enfam incorporou a disciplina questões de gênero na formação inicial de juízes.

Apresentaremos o referencial teórico utilizado nas aulas incorporando o debate trazido pelas feministas do direito e interseccional a partir das obras de Alda Facio, Bell Hooks e das brasileiras Sueli Carneiro e Carmen Hein de Campos.

Nesse sentido, o artigo divide-se em três seções. Na primeira, são colocadas as questões referentes aos estudos de gênero e violência contra a mulher, e mais propriamente, ao debate teórico de gênero como categoria de análise; na segunda, tratamos da obrigação constitucional e internacional em se lecionar questões de gênero no Poder Judiciário; na terceira e última, abordamos os desafios de se incorporar a perspectiva de gênero através da experiência da autora, enquanto formadora no módulo nacional da Enfam e os impactos das aulas nos juízes. 


\section{OS ESTUDOS DE GÊNERO E A VIOLÊNCIA CONTRA A MULHER}

Nas últimas décadas, ocorreram no Brasil avanços nos estudos de gênero coerentes com a importância que está sendo atribuída à epistemologia feminista. A sociologia, a antropologia e outras ciências humanas lançaram mão da categoria gênero para demonstrar as desigualdades socioculturais existentes entre homens e mulheres, que repercutem na esfera pública e privada de ambos os sexos, impondo a eles papéis sociais diferenciados, construídos historicamente. (TELES, 2003)

O movimento feminista brasileiro teve grande contribuição nos avanços dos estudos de gênero. Importante observarmos que boa parte das feministas eram acadêmicas quando foram criados os núcleos de estudos e pesquisas sobre gênero e sexualidade no âmbito das universidades. Como as acadêmicas circulavam internacionalmente expondo suas ideias, elas ocupavam uma "posição privilegiada para receber, elaborar e disseminar as novas questões que o feminismo colocara no final da década de 1960 nos países capitalistas avançados". (HEILBORN; SORJ, 1999, p. 3)

Os estudos de gênero, então, ganharam maior densidade na década de 1970, quando surgiram os primeiros grupos e núcleos de pesquisa e disciplinas sobre estudos feministas e de gênero. Vale lembrar que as pesquisas científicas realizadas antes desse período desconsideravam mais da metade da humanidade, visto que as mulheres não integravam as investigações que quase sempre consideram a perspectiva masculina.

No direito, o movimento feminista também começou a tecer fortes críticas às ciências e às diversas disciplinas acadêmicas desde a década de 1970, fazendo surgir uma área do conhecimento denominada "teoria feminista do direito", para algumas teóricas "feminismo jurídico" e como o patriarcado influencia juízes e juízas na interpretação e na aplicação das leis².

\footnotetext{
${ }^{2}$ Carol Smart identifica três estágios no desenvolvimento da ideia de que o direito é gendrado. Fundamentalmente, são fases de reflexão na teoria feminista que forneceram um alicerce de entendimento e que foram ampla, mas não completamente, superadas. O primeiro estágio é ilustrado pela frase "o direito é sexista"; segundo, "o direito é masculino", e, finalmente, chegamos ao ponto em que podemos alegar que "o direito é gendrado". É possível encontrar esses três níveis de argumentação empregados simultaneamente em alguns trabalhos feministas sobre o direito, mas é importante diferenciá-los para identificarmos a promessa analítica presente em cada abordagem. (SMART, 2020, p. 1.418)
} 
Uma das primeiras críticas feministas feitas ao direito parte de uma concepção de que homens e mulheres são iguais, possuem as mesmas capacidades e habilidades. Outra vertente da teoria crítica diz respeito ao argumento de que a falta de perspectiva de gênero no Poder Judiciário causa uma visão androcêntrica na aplicação e na interpretação das leis, que são neutras e objetivas (FAClO, 2002). Carmen Hein de Campos (2011) argumenta, por sua vez, que "analisar o direito ou categorias jurídicas a partir de uma perspectiva feminista implica trazer para o centro da análise 'as mulheres'”. A autora analisa o debate do uso do direito penal pelas feministas dado o seu caráter sexista e masculino. Segundo ela, a discussão

[...] deu-se em duas vertentes principais: a primeira, relacionada à sua utilização como um instrumento simbolicamente válido para garantir proteção, particularmente contra a violência doméstica e sexual, através de reformas legais. Assim, essa corrente impulsiona a criação de leis de proteção às mulheres, de penas mais duras e do controle da violência masculina. A segunda critica o uso do direito penal, pois entende como um campo negativo para as mulheres, como produtor de maior sofrimento e que descuida também dos homens violentos. (CAMPOS, 2020, p. 178)

A primeira corrente é adotada pelas juristas feministas e, a segunda, pelas criminólogas críticas feministas e não feministas.

A violência contra a mulher passou a ser um assunto político e visto como um problema social no início da década de 1980, a partir da grande repercussão dos assassinatos de mulheres de classe social mais elevada por seus maridos e companheiros, como por exemplo, Ângela Diniz, ocorrido na Praia dos Ossos, em Búzios, no Rio de Janeiro. Tudo começou quando Ângela, considerada uma mulher "avançada" para a época, resolveu colocar fim ao relacionamento amoroso conturbado que mantinha com Doca Street. Por não aceitar o término da relação, Doca Street efetuou quatro disparos de arma de fogo contra Ângela. Durante o seu julgamento, a defesa argumentou que o crime teria sido praticado por "legítima defesa da honra".

A partir da visibilidade de casos como o de Ângela Diniz e a absolvição pelos tribunais do júri dos autores de homicídios de mulheres sob a alegação da legítima defesa da honra, no início da década de 1980, surgiram grupos feministas em todo o país, denominados SOS-Mulher, que prestavam atendimento jurídico, psicológico e social às mulheres. 
A primeira delegacia de atendimento à mulher foi instalada em 1985, na cidade de São Paulo. Em seguida, vieram outras, em outros estados. Até hoje, trata-se de uma das principais políticas públicas de combate à violência contra a mulher no Brasil. (MORAES; SORJ, 2009)

A violência doméstica e familiar contra a mulher está entre os principais problemas enfrentados pelas mulheres no Brasil, conforme pesquisa realizada pelo Instituto Patrícia Galvão (2020), denominada Percepções, sobre estupro e aborto previsto em lei. Dados divulgados pelo Ipea, em 2018, revelam que 4.519 mulheres foram assassinadas no Brasil, o que representa uma taxa de 4,3 homicídios para cada 100 mil habitantes do sexo feminino. (INSTITUTO DE PESQUISA ECONÔMICA APLICADA, 2020)

A violência doméstica atinge todas as mulheres, independentemente de classe social, raça/cor, escolaridade ou religião. Um triste exemplo dessa realidade foi o recente feminicídio da juíza Viviane Amaral, às vésperas do Natal de 2020, no Rio de Janeiro, diante de suas três filhas pequenas. Foram 16 facadas. Soma-se a esse caso o de Mariângela Fontana Barbosa, de 25 anos, assassinada pelo marido na madrugada de $1^{\circ}$ de janeiro de 2021, em Curitiba. O requinte de crueldade dos crimes, geralmente com várias facadas e disparos de arma de fogo, revela o ódio e a misoginia por parte dos agressores (companheiros, maridos e namorados - ex ou atuais). Além disso, o inconformismo com o término da relação, a desconfiança de traição e o ciúme excessivo têm sido comuns nos crimes de feminicídio.

No artigo La capacidad transformadora del derecho en la violencia de género, Ana Rubio Castro (2007) defende a importância da legislação espanhola na proteção das mulheres que sofrem violência doméstica, visto que são elas as maiores vítimas dessa forma de violência naquele país. Assim, como no Brasil, critica o caráter reducionista da lei espanhola que poderia ter sido desenvolvida em dois planos distintos, um para a mulher vítima de violência no contexto das relações domésticas e afetivas, e outro para prever medidas de intervenção que reduziriam a opressão e a erradicação de outros privilégios. Isto porque a violência de gênero não é um problema entre sujeitos, nem é resultado de práticas individuais, senão a expressão de uma determinada divisão sexual do trabalho, de relações de poder assimétricas entre mulheres e homens e da permanência dos privilégios dos homens, tudo de forma a impedir que as mulheres desenvolvam sua subjetividade e cidadania em condições de igualdade. (CASTRO, 2007, p. 8) 
Em relação às questões raciais e de gênero, deve ser considerado que os estereótipos de gênero e racistas, "como da mulher negra de força sobre-humana", são mitos que povoam as mentes de muitas mulheres brancas, o que permite que elas ignorem até que ponto as mulheres negras são vítimas em potencial da sociedade, esquecendo, por outro lado, o papel que as mulheres brancas tendem a exercer na manutenção e na perpetuação da vitimização. (HOOKS, 2020, p. 44)

Vale lembrar que as mulheres negras são as maiores vítimas de violência doméstica e de feminicídio no Brasil, violência obstétrica e assédio sexual (FÓRUM BRASILEIRO DE SEGURANÇA PÚBLICA, 2021). O mito da democracia racial e a falta de políticas públicas para enfrentar o racismo no Brasil tem levado a violência contra as populações negras a números alarmantes no Brasil 3 .

A desigualdade de poder nas relações conjugais, a complexidade do fenômeno da violência de gênero e o racismo, que devem ser vistos como um problema estrutural e não apenas como um conflito intersubjetivo entre parceiros íntimos, ex ou atuais, o sentimento de posse e propriedade que alguns homens possuem em relação aos corpos femininos e negros são temas que precisam ser inseridos nas aulas e debatidos pelos(as) juízes(as) nas formações iniciais e continuadas, além da importância da atuação e do julgamento com perspectiva de gênero e de raça.

De acordo com o informe da Comissão Interamericana de Direitos Humanos - CIDH sobre o acesso à justiça pelas mulheres vítimas de violência nas Américas, elas enfrentam graves dificuldades e barreiras significativas para obterem o direito fundamental de acesso à justiça, em razão de vários fatores. Para tanto, é indispensável que o Estado e a sociedade em geral compreendam que o acesso à justiça é fundamental e reconheçam que a violência e a discriminação contra as mulheres não são fenômenos isolados, mas produto de uma violência estrutural que atinge todo o tecido social, em tempo de paz, de guerra ou em situações regulares. (ORGANIZACIÓN DE LOS ESTADOS AMERICANOS, 2007)

O reconhecimento pelos(as) juízes(as) de que a discriminação e a violência de gênero afetam de forma desproporcional as mulheres, que afrontam o direito à igualdade e impactam no direito de acesso à justiça,

\footnotetext{
3 Vide: morte da jovem Kathlen Romeu, designer de interiores, que tinha 24 anos e estava grávida de 14 semanas quando foi atingida com um tiro de fuzil no tórax, na comunidade do Lins de Vasconcelos, no Rio de Janeiro. (G1, 2021)
} 
é fundamental para que as mulheres possam contar com um sistema de justiça livre de mitos e de estereótipos, com um Poder Judiciário imparcial e sem compromissos com pressupostos tendenciosos (Recomendação n. 33 do Comitê Cedaw) (NAÇÕES UNIDAS, 2015). Portanto, eliminar os estereótipos de gênero no âmbito do Poder Judiciário é um passo relevante na garantia da igualdade e justiça para vítimas e sobreviventes. Nesse sentido, a perspectiva de gênero deve ser incorporada nos conteúdos e nos currículos de todas das formações judiciais no âmbito das escolas da magistratura, de forma transversal e em todos os aspectos do sistema de justiça.

\section{A FORMAÇÃO EM QUESTÕES DE GÊNERO NO PODER JUDICIÁRIO}

Pesquisas, documentos e informes internacionais indicam que as mulheres enfrentam obstáculos e restrições quando acessam o sistema de justiça ${ }^{4}$, daí a necessidade de que o ensino jurídico, ainda bastante conservador, seja reformulado. Em grande parte, os(as) operadores(as) do direito o compreendem como instrumento de regulação e de conservação da ordem social, e não como instrumento de emancipação. Por isso, a relevância de se incluir na formação judicial temas relativos aos direitos humanos a partir de uma perspectiva de gênero, considerando que o direito sempre foi interpretado e aplicado com base no paradigma masculino e discriminatório em relação à mulher.

Alda Facio (2012) assinala que o direito é composto por três classes de normas que poderiam ser qualificadas como direito legislativo, judicial e material ou real. A autora aponta uma crítica feita pelas teóricas feministas do direito de que não só o direito em sentido estrito, como também o direito em sentido amplo, são fenômenos que excluem as mulheres tanto da sua prática quanto da sua teoria. E que isso é relevante entender porque geralmente se acredita que se não há discriminação explícita nas leis e nos códigos de um determinado país, então, não há

\footnotetext{
${ }^{4}$ Pesquisa realizada pelo Ipea/CNJ aponta que "a ausência de informações às mulheres é o padrão encontrado nas demais unidades pesquisadas. No geral, as mulheres não distinguem as etapas do processo, o objetivo e as implicações de cada fase, o que podem ou não esperar. Geralmente, até o momento da primeira audiência, as únicas informações que elas receberam são aquelas fornecidas na delegacia. Ao mesmo tempo, nem sempre as informações que são transmitidas nas audiências são esclarecidas e suficientes". (CONSELHO NACIONAL DE JUSTIÇA; INSTITUTO DE PESQUISA ECONÔMICA APLICADA, 2019, p. 103)
} 
discriminação legal, portanto, as estratégias para eliminar a discriminação real não são efetivas, visto que parte de diagnósticos equivocados.

Boaventura de Sousa Santos (2011) afirma que o paradigma jurídico-dogmático domina o ensino nas faculdades de direito que não conseguem ver que na sociedade circulam várias formas de poder, de direito e de conhecimento que superam os seus postulados, "distantes das preocupações sociais e têm servido, em regra, para a formação de profissionais sem maior comprometimento com os problemas sociais". (SANTOS, 2011, p. 87)

Em relação às escolas da magistratura, Boaventura de Sousa Santos (2011, p. 95) afirma que a criação de uma cultura jurídica democrática passa pela transformação das faculdades de direito, mas também pela transformação dos modelos de recrutamento e de formação dos juízes, até porque eles podem reproduzir os erros das faculdades de direito e, mais grave, aprofundá-los. Em Portugal, propôs-se que nessas escolas apenas 50\% dos professores sejam juristas, e que os demais venham de outras formações, principalmente nas áreas da infância e família. Isso porque, muitos juízes(as) têm uma formação jurídica antiquada, sem nenhum conhecimento na área da infância ou família, por exemplo.

O mesmo pode ocorrer nos juizados de violência doméstica e familiar contra a mulher quando juízes(as) não têm formação em gênero e direitos humanos. As consequências são graves para as mulheres. Em casos de violência sexual, por exemplo, a ausência de perspectiva de gênero pode fazer com que juízes(as) deem pouca credibilidade e peso às vozes e aos argumentos das mulheres, tratamento inadequado às vítimas e seus familiares, o que causará sérios impactos e imporá obstáculos no seu direito fundamental de viver uma vida livre de violência e, consequentemente, no seu direito de acesso à justiça.

O direito internacional de direitos humanos estabelece uma série de obrigações aos estados relacionados à administração da justiça e aos direitos das mulheres, como a garantia do direito de acesso à justiça em condições de igualdade a todas as pessoas que se encontram no seu território, o que inclui: a) garantir o devido processo legal (para tanto, o Estado deve considerar as desigualdades de gênero, de raça/ etnia, deficiência); e b) estabelecer garantias judiciais que considerem as necessidades de todas as pessoas, dentre outras: i) serem parte em processo judicial em condições de igualdade; ii) não serem revitimizadas no processo judicial; iii) serem aceitas e protegidas como testemunhas; 
iv) participarem e compreenderem o processo; e v) gozarem dos serviços judiciais em condições de igualdade e de informação judicial que oriente a usuária e facilite a tomada de decisões sem preconceitos sexistas. (VARGAS, 2011, p. 65)

A socióloga britânica Carol Smart (2020), considerada uma das pensadoras fundamentais do feminismo contemporâneo, identifica três estágios no desenvolvimento da ideia de que o direito é gendrado. 0 primeiro deles é ilustrado pela frase "o direito é sexista"; o segundo, por "o direito é masculino", e, finalmente, chegamos ao ponto em que podemos alegar que "o direito é gendrado".

Soraia da Rosa Mendes (2020, p. 93) argumenta que "o direito não passa incólume ao simbolismo de gênero e menos ainda do patriarcado". As instituições do sistema de justiça criminal também reproduzem as desigualdades de gênero e reforçam os estereótipos e preconceitos de gênero. A autora menciona os argumentos ainda utilizados nos processos como o "de proteger a família", "defender a honra" e "garantir o pátrio poder", muitas vezes empregados nas fundamentações das decisões e sentenças de absolvição de réus de agressão doméstica e sexual contra as mulheres, que reforçam o que Ana Lucia Sabadell denomina de "patriarcalismo jurídico". (SABADELL; PAIVA, 2019)

Visando enfrentar essa situação e atender às recomendações internacionais do Comitê Cedaw da ONU55, a Enfam e as escolas da magistratura vêm desenvolvendo um papel relevante ao incorporar em seus cursos temas relacionados aos direitos das pessoas vulneráveis, violência de gênero contra as meninas e mulheres, identidade de gênero e população LGBTQI+, questões raciais, pessoas com deficiência, infância e adolescência, questões indígenas e quilombolas, dentre outros temas relevantes de direitos humanos, tanto na formação inicial quanto na continuada.

feminismo e a epistemologia feminista têm trazido avanços para as ciências jurídicas, no entanto, ainda mantemos a tradição dos estudos do direito com enfoque na dogmática jurídica, com viés privatista e formalista (PIOVESAN, 2012). Os estudos de gênero no direito são recentes no Brasil e, até hoje, o tema encontra resistência nas faculdades de direito e nas formações dos operadores da justiça. Poucas universidades possuem núcleos de pesquisa em gênero e

\footnotetext{
${ }_{5}$ Recomendações n. 33 e n. 35 do Comitê Cedaw da ONU. (CONSELHO NACIONAL DE JUSTIÇA, 2019; NAÇÕES UNIDAS, 2015)
} 
direito, disciplinas sobre teoria feminista do direto e com a perspectiva de gênero. Se o feminismo jurídico vem atuando há décadas para compreender e explicar a discriminação institucional que as mulheres enfrentam quando precisam acionar o sistema de justiça, seria razoável que o ensino jurídico fosse reformulado para incluir nos currículos das disciplinas a perspectiva de gênero, que serviria de guia de reforma para todas aquelas instituições que ocasionam a violência institucional contra as mulheres (CASTRO, 2007, p. 8). A resistência quanto aos estudos de gênero no direito reside em razão do preconceito e da discriminação existente na sociedade brasileira despertados pelo tema, ainda por parte dos operadores da justiça. Mas, com base na minha experiência empírica, como formadora da Enfam, tem sido enriquecedor ensinar na formação inicial, ante os resultados alvissareiros obtidos.

Nessa linha, é importante que juízas(es) assumam outro compromisso político e social com a profissão, conforme avalia Caetano Ernesto da Fonseca Costa (2020, p. 37), "não para esquecer, evidentemente, as raízes do estado democrático, mas ao contrário, para reafirmá-lo, e para enxergá-lo em outra dimensão, em que a magistratura há de cumprir sua verdadeira vocação de fazer valer a ética do direito".

\section{DO TEMA “QUESTÕES DE GÊNERO” NA FORMAÇÃO JUDICIAL}

Iniciei meus estudos de gênero no curso de mestrado em sociologia jurídico-penal pela Universidade de Barcelona em 2011. Ali, pela primeira vez, deparei-me com uma aula especialmente sobre violência de gênero, ministrada pela professora Encarna Bodelón (UAB) que, mais tarde, viria a ser minha orientadora da tese de doutoramento. Assim, foi uma professora de filosofia do direito que me apresentou um novo campo de estudo: a teoria feminista do direito.

Frequentei, como aluna, o primeiro curso de Formação de Formadores - Fofo pela Enfam em 2016, onde conquistei grandes amizades na sala de aula e na magistratura que resultaram numa enorme mudança de paradigma na minha vida: a paixão pela educação judicial de gênero. Durante as formações, aprendi como usar as metodologias ativas, trabalhar estratégias de ensino que fazem os(as) alunos(as) refletirem sobre a sua prática na magistratura. Hoje, posso afirmar tranquilamente que lecionar faz parte da minha carreira na magistratura. 
O ensino de gênero é relevante porque estamos vivendo um mundo genereficado e, quando falamos em gênero, falamos das nossas vidas, dos nossos papéis sociais, como magistrada(o), mãe e pai, filhos e filhas, e como cidadãos e cidadãs, como pessoas que vêm de uma sociedade ainda muito estruturada no patriarcado, no sexismo e no racismo.

Ao longo do meu processo de formação na Enfam, li algumas obras de Paulo Freire e da Bell Hooks (2017), como Ensinando a transgredir, A educação como prática da liberdade e Pedagogia da autonomia, que me despertaram para outra forma de ensinar. Com eles, aprendi que "a educação só pode ser libertadora quando todos tomam posse do conhecimento como se fosse uma plantação em que todos temos de trabalhar" (HOOKS, 2017, p. 26). Isso me encorajou a criar estratégias para a sensibilização sobre gênero em sala de aula. No entanto, não foi uma tarefa fácil.

Conforme destaca Paulo Freire, "saber ensinar não é transferir conhecimento, mas criar as possibilidades para sua própria produção ou a sua construção". O método ativo ou participativo é melhor do que o ensino tradicional, principalmente na educação judicial, onde pressupõese que o(a) juiz(a) possui os conhecimentos teóricos e o conhecimento das leis e normas necessários para julgar. O importante nas aulas é fazê-lo(a) refletir sobre o seu papel na sociedade, sobre a sua vida e sua história, e como isso pode influenciar positiva ou negativamente nos seus julgamentos.

Um trecho, em especial, da obra de Bell Hooks (2017, p. 35) me emociona:

Quando a educação é a prática da liberdade, os alunos não são os únicos chamados a partilhar, a confessar. A pedagogia engajada não busca simplesmente fortalecer e capacitar os alunos. Toda sala de aula em que for aplicado um modelo holístico de aprendizado será também um local de crescimento para o professor, que será fortalecido e capacitado por esse processo. Esse fortalecimento não ocorrerá se nos recusamos a nos abrir ao mesmo tempo em que encorajamos os alunos a correr riscos.

Os ensinamentos de Bell Hooks me levaram a refletir sobre o meu papel nas formações judiciais e a estar totalmente presente em mente, corpo e espírito. Até porque os(as) juízes(as) acabaram de ingressar na carreira jurídica através de um concurso público extremamente difícil, 
dominam bastante a parte teórica do direito, mas poucos têm a prática e a vivência com o tema gênero e violência doméstica. E falar sobre gênero é falar sobre as nossas vidas e experiências.

Ensinar a interpretar o direito com as lentes de gênero é uma obrigação constitucional e convencional e se converte em uma ferramenta analítica que busca explicar o fenômeno da desigualdade entre homens e mulheres, permite identificar, questionar e valorar a discriminação, a desigualdade e a exclusão das mulheres.

Durante as aulas, são transmitidos vídeos e discutidos textos e casos concretos de violação de direitos humanos das mulheres que muitos juízes(as) nem sequer tinham ciência da existência ou ouvido falar durante a faculdade nem Ihes foram exigidos nos concursos públicos. Mas tudo isso pode ser debitado às críticas dirigidas ao ensino jurídico brasileiro, ainda pautado numa visão privatista e no dogmatismo jurídico.

Nestes cinco anos de experiência de ensino na formação judicial, percebi, não raras vezes, que os juízes se emocionam ao partilhar em sala de aula a sua trajetória de vida, dificuldades, conquistas e derrotas, relatos pessoais e familiares sobre preconceito e discriminação de gênero que viveram ou presenciaram. Trazer a realidade brasileira para as salas de aula das escolas da magistratura acerca das desigualdades sociais, políticas e econômicas, raciais e de gênero é fundamental para aprimorar a qualidade da justiça.

\section{CONCLUSÃO}

Diante do exposto, dos obstáculos e dos desafios apresentados, duas vertentes podem ser colocadas. A primeira delas é a importância dos estudos de gênero e dos direitos humanos das mulheres no ensino jurídico brasileiro, impondo-se uma reforma do sistema de maneira a contemplar a perspectiva de gênero na doutrina jurídica, que seja capaz de dar visibilidade à mulher e tornar visíveis as relações entre os gêneros.

A cultura jurídica precisa ser reformulada para incorporar os direitos humanos desde uma perspectiva de gênero, iniciando-se pelo ensino jurídico e alcançando o sistema de recrutamento e formação de juízes(as) que atenda aos anseios da sociedade e "que leve os cidadãos e cidadãs a sentirem-se mais próximos da justiça". (SANTOS, 2011, p. 124) 
A outra vertente refere-se à importância da formação a partir de uma perspectiva de gênero em todas as áreas do Poder Judiciário. Essa nova concepção do direito deve considerar o padrão de discriminação e de preconceito sofrido pelas mulheres ao acessarem a justiça. Ainda prevalece a ideia de que o(a) magistrado(a), ao ingressar na carreira judicial, através do concurso público, não precisa mais se atualizar, visto que é dotado de formação e de qualificação para a vida toda. Mas não é nem deve ser assim.

Para a garantia do direito de acesso à justiça pelas mulheres é fundamental que os operadores da justiça considerem os aportes da Corte Interamericana de Direitos Humanos - CIDH, que desenvolveu o conceito doutrinário de corpus juris dos direitos humanos e a técnica de interpretação para a abordagem adequada nos casos de vítimas de violência contra as mulheres ${ }^{6}$.

Todos nós precisamos nos capacitar e complementar nossa formação com cursos em temas especializados e atualizados, especialmente no Brasil, país com tantas mazelas e repleto de desigualdades sociais, políticas e econômicas, que afetam de forma desproporcional meninas e mulheres. Temos, nós juízes, muitos desafios a enfrentar e apenas com a formação voltada aos direitos humanos e a partir de uma perspectiva de gênero seremos capazes de fazer uma revolução democrática da justiça.

\footnotetext{
${ }^{6} \mathrm{Na}$ opinião consultiva OC-16/1999. A CIDH declarou que "115. O corpus juris do Direito Internacional dos Direitos Humanos é formado por um conjunto de instrumentos internacionais de conteúdo e efeitos jurídicos variados (tratados, convênios, resoluções e declarações). A sua evolução dinâmica tem exercido um impacto positivo no direito internacional, no sentido de afirmar e desenvolver a aptidão deste último, para regular as relações entre os Estados e os seres humanos, sob as suas respectivas jurisdições. Portanto, esta Corte deve adotar um critério adequado para considerar a questão sujeita a exame, no âmbito da evolução dos direitos fundamentais da pessoa humana, no direito internacional contemporâneo". (CORTE INTERAMERICANA DE DIREITO HUMANOS, 1999)
} 


\section{REFERÊNCIAS}

CAMPOS, Carmen Hein de. Criminologia feminista: teoria feminista e crítica às criminologias. 2. ed. Rio de Janeiro: Lumen Juris, 2020.

CAMPOS, Carmen Hein de. Razão e sensibilidade: teoria feminista do direito e Lei Maria da Penha. In: CAMPOS, Carmen Hein de (org.). Lei Maria da Penha: comentada em uma perspectiva jurídico-feminista. Rio de Janeiro: Lumen Juris: 2011, p. 1-12. Disponível em: https://assetscompromissoeatitude-ipg.sfo2.digitaloceanspaces.com/2014/02/1_1_ razao-e-sensibilidade.pdf. Acesso em: 8 fev. 2021.

CARNEIRO, Sueli. Enegrecer o feminino: a situação da mulher negra na América Latina a partir da perspectiva de gênero. Estudos avançados, São Paulo, v. 17, n. 49, 2003. Disponível em: https://www.scielo.br/pdf/ ea/v17n49/18400.pdf. Acesso em: 8 fev. 2020.

CASTRO, Ana Rubio. La capacidad transformadora del derecho en la violencia de género. Circunstância: Revista de Ciencias Sociales del Instituto Universitario de Investigación Ortega y Gasset, Madrid, n. 12, p. 8, 2007.

\section{CONSELHO NACIONAL DE JUSTICCA (Brasil). Recomendação Geral}

n. 35 sobre violência de gênero contra as mulheres do Comitê para eliminação de todas as formas de discriminação contra a mulher

(Cedaw). Tradução Neri Accioly. Brasília, DF: Conselho Nacional de Justiça (CNJ), 2019. (Série Tratados Internacionais de Direitos Humanos). Disponível em: https://www.cnj.jus.br/wp-content/ uploads/2019/09/769f84bb4f9230f283050b7673aeb063.pdf. Acesso em: 13 jun. 2021.

CONSELHO NACIONAL DE JUSTICCA (Brasil); INSTITUTO DE PESQUISA ECONOMICA APLICADA. O Poder Judiciário no enfrentamento à violência doméstica e familiar contra as mulheres: relatório. Brasília, DF: Conselho Nacional de Justiça (CNJ), 2019. Disponível em: https://www.cnj.jus.br/wp-content/uploads/conteudo/ arquivo/2019/08/7b7cb6d9ac9042c8d3e40700b80bf207.pdf. Acesso em: 13 jun. 2021.

CORTE INTERAMERICANA DE DIREITO HUMANOS. Opinião Consultiva n. 16/99, de 1 de outubro de 1999, solicitada pelos Estados Unidos Mexicanos. O direito à informação sobre a assistência consultar no âmbito das garantias do devido processo legal. Costa Rica: [s.n.], 
1999. Disponível em: http://www.pge.sp.gov.br/centrodeestudos/ bibliotecavirtual/interamericano/21210opiniao.htm. Acesso em: 20 jun. 2021.

COSTA, Caetano Ernesto da Fonseca. Para além da escuridão: por uma justiça emancipatória. Campos dos Goytacazes, RJ: Encontrografia, 2020.

ESCOLA NACIONAL DE FORMAÇÃO E APERFEIÇOAMENTO DE MAGISTRADOS (Brasil). Sobre a Enfam. Brasília, [2021]. Disponível em: https://www.enfam.jus.br/institucional/sobre-a-escola. Acesso em: 7 fev. 2021.

FACIO, Alda. Con los lentes del género se ve otra justicia. El otro derecho, Bogotá, n. 28, p. 85-102, 2002.

FÓRUM BRASILEIRO DE SEGURANÇA PÚBLICA. Visível e invisível: a vitimização de mulheres no Brasil. 3. ed. [S.I.: s.n.], 2021. Disponível em: https://forumseguranca.org.br/wp-content/uploads/2021/06/relatoriovisivel-e-invisivel-3ed-2021-v3.pdf. Acesso em: 17 jun. 2021.

G1. O que se sabe sobre a morte da jovem Kathlen Romeu, no Rio. Rio de Janeiro, 2021. Disponível em: https://g1.globo.com/rj/rio-de-janeiro/ noticia/2021/06/10/o-que-se-sabe-sobre-a-morte-da-jovem-kathlenromeu-no-rio.ghtml. Acesso em: 13 jun. 2021.

HEILBORN, Maria Luiza; SORJ, Bila. Estudos de gênero no Brasil. In: MICELI, Sérgio (org.). O que ler na ciência social brasileira (1970-1995). São Paulo: ANPOCS, 1999.

HOOKS, Bell. Teoria feminista. São Paulo: Perspectiva, 2020.

HOOKS, Bell. Ensinando a transgredir: a educação como prática da liberdade. São Paulo: Martins Fontes, 2017.

INSTITUTO PATRÍCIA GALVÃO. Pesquisa: percepções sobre estupro e aborto previsto por lei. Disponível em: https://assets-institucionalipg.sfo2.cdn.digitaloceanspaces.com/2020/11/Locomotiva_IPG_

EstuproeAbortoPrevistoPorLeiNovembro2O2O-1.pdf. Acesso em: 17 jun. 2021.

INSTITUTO DE PESQUISA ECONOMICA APLICADA (Brasil). Atlas da Violência. 2020. Brasília: IPEA, 2020. Disponível em: https:// forumseguranca.org.br/wp-content/uploads/2020/08/atlas-daviolencia-2020.pdf. Acesso em: 17 jun. 2021. 
MENDES, Soraia da Rosa. Processo penal feminista. São Paulo: Atlas, 2020.

MARIA et al. [Carta das mulheres aos constituintes]. Destinatário: Aos constituintes de 1987 Assembleia Nacional Constituinte Congresso Nacional. Brasília, 1987. 1 carta. Disponível em: https://www2.camara. leg.br/atividade-legislativa/legislacao/Constituicoes_Brasileiras/ constituicao-cidada/a-constituinte-e-as-mulheres/arquivos/ Constituinte\%201987-1988-Carta\%20das\%20Mulheres\%20aos\%20 Constituintes.pdf. Acesso em: 8 fev. 2020.

MORAES, Aparecida Fonseca; SORJ, Bila (org.). Gênero, violência e direitos na sociedade brasileira. Rio de Janeiro: 7 Letras, 2009.

NAÇÕES UNIDAS. Comitê Sobre a Eliminação da Discriminação Contra as Mulheres. Recomendação Geral n. 33 sobre acesso das mulheres à justiça, do Comitê CEDAW. [S./.] 2015. Disponível em: https://assetscompromissoeatitude-ipg.sfo2.digitaloceanspaces.com/2016/02/ Recomendacao-Geral-n33-Comite-CEDAW.pdf. Acesso em: 7 fev. 2021.

ORGANIZAÇÃO DOS ESTADOS AMERICANOS. Comissão Interamericana de Direitos Humanos. Acceso a la Justicia para las mujeres víctmas de violência em las Américas. Washington, D.C: Organización de los Estados Americanos, Secretaría General, 2007. Disponível em: https://www.cidh.oas.org/pdf\%20files/Informe\%20 Acceso\%20a\%20la\%20Justicia\%20Espanol\%20020507.pdf. Acesso em: 20 jun. 2021.

PIOVESAN, Flávia. Temas de direitos humanos. 5. ed. São Paulo: Saraiva, 2012.

SABADELL, Ana Lucia; PAIVA, Lívia de Meira Lima. La actuación de las instituciones del sistema de justicia brasileño en la elaboración de acciones de combate a la violencia doméstica. Studi sulla Questione Criminale, Roma, v. 14, n.1-2, p. 107-130, 2019.

SANTOS, Boaventura de Sousa. Para uma revolução democrática da justiça. 3. ed. São Paulo: Cortez, 2011.

SMART, Carol. A mulher do discurso jurídico. Tradução: Alessandra Ramos de Oliveira Harden. Revista Direito e Práxis, Brasília, v. 11, n. 2, p. 1.418-1439, 2020. 
TELES, Maria Amélia de Almeida. O que é violência contra a mulher. São Paulo: Brasiliense, 2003.

VARGAS, Roxana Arroyo. Acceso a la justicia para las mujeres... el laberinto androcéntrico del derecho. Revista IIDH, San José, CR, n. 53, p. 35-62, 2011. Disponível em: https://www.corteidh.or.cr/tablas/r26673. pdf. Acesso em: 20 jun. 2021. 